\title{
Functionalized 2-Hydroxybenzaldehyde-PEG Modules as Portable Tags for the Engagement of Protein Lysine $\varepsilon$-Amino Groups
}

\author{
Giovanni Sacco, ${ }^{[\mathrm{a}]}$ Simon Stammwitz, ${ }^{[\mathrm{a}]}$ Laura Belvisi, $^{[\mathrm{a}]}$ Luca Pignataro, $^{[\mathrm{a}]}$ Alberto Dal Corso, ${ }^{*[\mathrm{a}]}$ \\ and Cesare Gennari*[a]
}

Dedicated to Prof. Franco Cozzi on the occasion of his $70^{\text {th }}$ birthday.

The formation of reversible-covalent interactions between a small-molecule ligand and its protein target is emerging as a general strategy to design binders with increased affinity. In this context, 2-hydroxybenzaldehyde (2HB) has been recently proposed as suitable electrophilic tag to engage primary amines, such as the $\varepsilon$-amino group of lysine residues, in remarkably stable imines. Lys residues are often expressed in high amounts on protein surfaces and in the proximity of ligand binding sites, and a fine-tuning of the chemical connection between the ligand and $2 \mathrm{HB}$ is fundamental for the affinity gain. Herein we report the synthesis of four $2 \mathrm{HB}$ tags functionalized with a short polyethylene glycol (PEG) spacer and a suitable reactive 'handle' (alkyne, azide, carboxylic acid and amine, respectively) for their conjugation to virtually any type of small molecule ligand.

Over the last decades, monoclonal antibodies (mAbs) have played a leading role in modern pharmaceutical research, thanks to their unique ability to bind biological targets with high affinity and selectivity. However, the systematic identification of high-affinity small ligands (e.g. peptides, peptidomimetics) may represent a valid alternative to the use of mAbs, especially whenever antigen binding is hindered by physical barriers (e.g. extravasation, diffusion through the cell membrane, etc.). In this context, there is a considerable interest in the generation of small molecule ligands with antibody-like affinity. To this end, several approaches are possible, such as: i) screening of large compound libraries; ${ }_{i}^{[1]}$ ii) rational design of multivalent structures; ${ }^{[2]}$ iii) ligand functionalization with electrophilic moieties forming irreversible ${ }^{[3]}$ or reversible ${ }^{[4]}$ covalent bonds with nucleophilic residues of the protein. Within the latter strategy, the 'reversible-covalent approach' is particularly

[a] G. Sacco, S. Stammwitz, Prof. Dr. L. Belvisi, Prof. Dr. L. Pignataro, Dr. A. Dal Corso, Prof. Dr. C. Gennari

Dipartimento di Chimica, Università degli Studi di Milano

Via C. Golgi, 19, 20133 Milan, Italy

E-mail: alberto.dalcorso@unimi.it cesare.gennari@unimi.it

https://sites.unimi.it/gennarigroup/

Supporting information for this article is available on the WWW under https://doi.org/10.1002/ejoc.202100160

Part of the "Franco Cozzi's 70th Birthday" Special Collection. attractive: in addition to the usual ligand-protein interactions (e.g. H-bonds, electrostatic and Van der Waals forces), covalent bond formation further stabilizes the ligand-protein complex (Figure $1 \mathrm{~A}$ ), while the reverse bond-breaking reaction avoids non-specific ligand binding.

Ortho-substituted aromatic aldehydes can form imine bonds under aqueous conditions with significant stability towards hydrolysis, allowing their exploitation as amine-engaging agents in reversible-covalent, ${ }^{[5]}$ as well as in other biochemical applications. $^{[6]}$

Following early reports by Gois and co-workers on 2-formylphenylboronic acids, ${ }^{[7]}$ researchers at AstraZeneca installed this motif on a small molecule inhibitor of induced myeloid leukemia cell differentiation protein $\mathrm{Mcl}-1 .^{[8]}$

This aldehyde derivative engaged the $\varepsilon$-amino group of a non-catalytic Lys residue proximal to the ligand binding site, in a reversible iminoboronate bond, thus increasing both binding affinity and pharmacological effects. Similarly, 2-hydroxybenzaldehyde (2HB) tags have also been used to strengthen ligandprotein interactions through imine formation with amine residues, which are stabilized by the intramolecular $\mathrm{H}$-bond between the imine $\mathrm{N}$ atom and the ortho-phenolic proton (Figure 1 A). Neri and co-workers demonstrated that the presence of the $2 \mathrm{HB}$ motif can increase the binding affinity of a panel of ligands for their cognate receptors. ${ }^{[10]}$ The original ligand binding affinity was restored by "quenching" the $2 \mathrm{HB}$ tag with a stoichiometric excess of hydroxylamine.

Overall, the above-mentioned and also other studies ${ }^{[11]}$ demonstrate that the affinity of ligands specific for a given biological target may be increased, when primary amino groups are present in the surroundings of the binding site, by ligand conjugation to $2 \mathrm{HB}$. In particular, lysine is commonly considered a "high-frequency" residue, ${ }^{[6]}$ and several reactive and solvent-exposed $\varepsilon$-amino groups often surround the binding pocket (Figure 1B-E). Thus, a proper design of reversible-covalent ligands should take into account: i) the presence and location of Lys residues in the protein structure, ii) the ligand pose into the binding pocket, and iii) the conjugation sites in the ligand structure suitable for the $2 \mathrm{HB}$ tag installation (Scheme 1A). It is also expected that length and flexibility of the spacer connecting the ligand and $2 \mathrm{HB}$ tag will strongly affect the ability of the conjugate to engage Lys $\varepsilon$-amino groups, thus improving the binding efficacy. Readily 
A
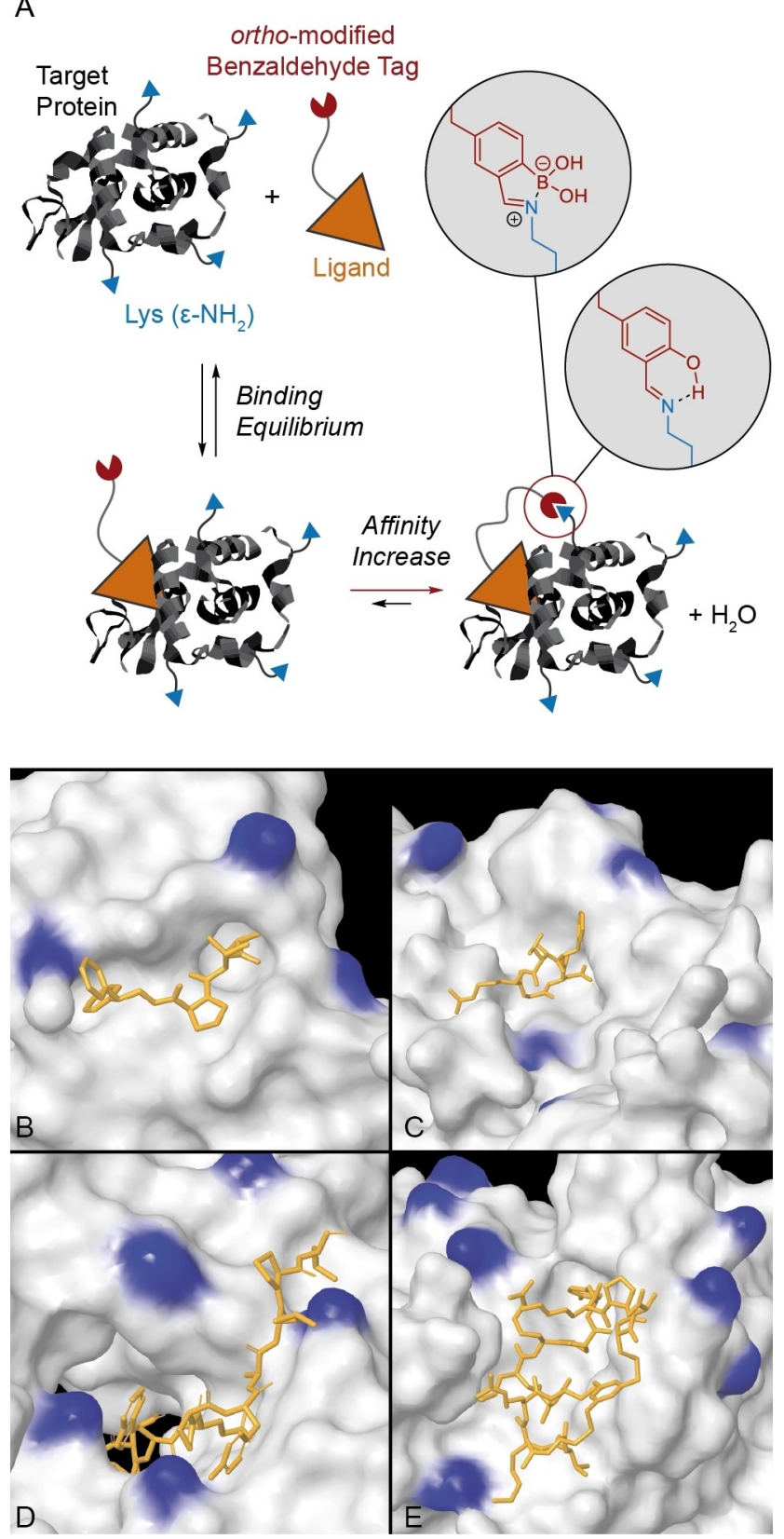

Figure 1. A) Schematic representation of the ideal binding mode of a generic protein ligand equipped with an ortho-modified benzaldehyde tag (i.e. 2formyl phenylboronic acid ${ }^{[8]}$ or 2-hydroxy benzaldehyde $\left.{ }^{[10]}\right)$, where the reversible imine formation with proximal $\varepsilon$-amines of Lys residues provides an additional stabilization of the ligand-protein complex. B-E) Examples of literature-available crystal structures of peptide/peptidomimetic ligands (orange) in the binding pockets of the relative protein targets (B: ML-IAP; C: integrin $\alpha_{v} \beta_{3}$; D: IL1R1; E: RBBP4) ${ }_{1}^{[9]}$ showing a high density of solventexposed $\varepsilon$-amine groups of Lys residues (highlighted in blue) in close proximity to the ligand binding site.

accessible $2 \mathrm{HB}$ derivatives, possessing different types of spacers and reactive handles, would be a key tool to conjugate the $2 \mathrm{HB}$ tag to a variety of protein ligands. Among the possible spacers, polyethylene glycol (PEG) has found widespread application in biotherapeutics, owing to its optimal physical-chemical properties (high water solubility, stability,

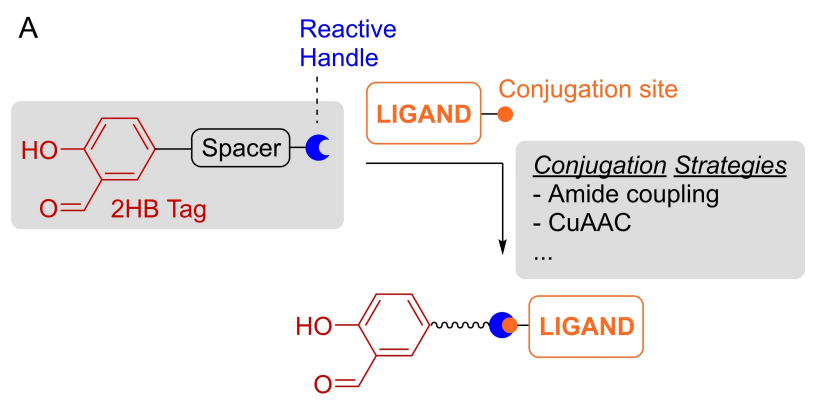

Reversible-Covalent Ligand

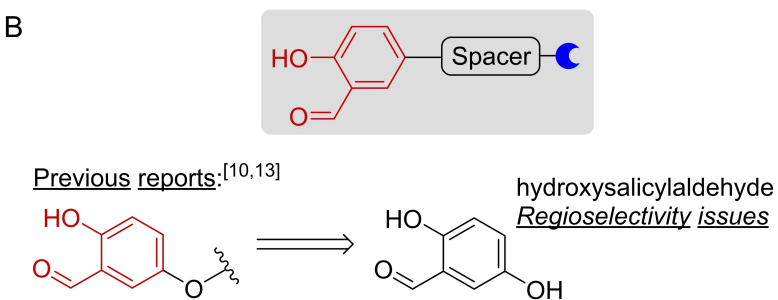

This work:

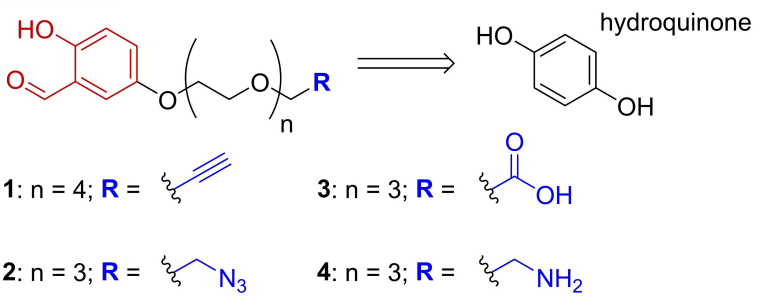

Scheme 1. A) Modular synthetic approach to reversible-covalent ligands, where a specific functional group (conjugation site) in the ligand structure and a reactive handle on the $2 \mathrm{HB}$-spacer module act as partners in a chemoselective reaction. B) Molecular structure of the $2 \mathrm{HB}$-spacer modules 1-4, featuring a PEG3 or PEG4 spacer and four different reactive handles (alkyne, azide, carboxylic acid and amine) for $2 \mathrm{HB}$ conjugation to the protein ligands via either cycloaddition or amide coupling.

flexibility) and its availability in a wide length range. ${ }^{[12]}$ Previously reported synthetic approaches to $2 \mathrm{HB}$ modules rely on the alkylation of hydroxysalicylaldehydes ${ }^{[10,13]}$ and are characterized by regioselectivity issues, low yields and difficult isolation of the desired mono-alkylated products from the reaction mixture (Scheme $1 \mathrm{~B}$ ).

Herein, we report a more practical synthetic approach to $2 \mathrm{HB}$ modules (Scheme 1B), consisting in the mono-alkylation of hydroquinone with a polyethylene glycol (PEG) chain, followed by regioselective phenol ortho-formylation with paraformaldehyde under the Skattebøl conditions. ${ }^{[14]}$ We planned the synthesis of four 2HB modules (compounds 1-4 in Scheme 1B), each possessing a functional group (reactive handle) for ligand conjugation by either cycloaddition reactions ${ }^{[15]}$ or amide coupling.

The synthesis of compound 1 (Scheme 2) started with the mono-propargylation of commercially available tetraethylene glycol (PEG4) following a literature procedure: ${ }^{[16]}$ tetraethylene glycol was treated with sodium hydride in dry THF and then propargyl bromide was slowly added at $0^{\circ} \mathrm{C}$, leading to alkyne 

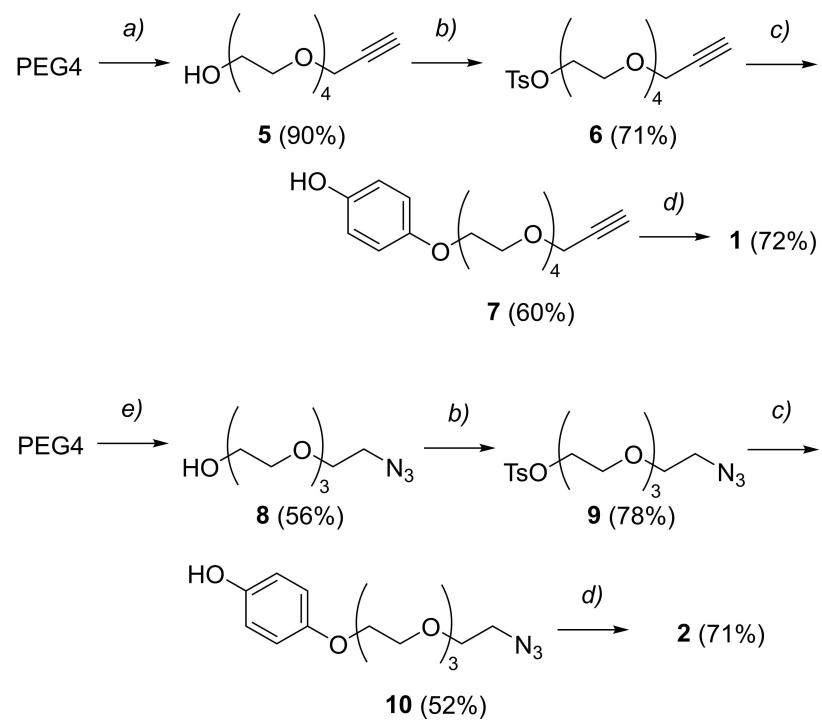

Scheme 2. Synthesis of 2HB-spacer modules 1 and 2. Reagents and conditions: a) propargyl bromide, $\mathrm{NaH}, \mathrm{THF}, 0{ }^{\circ} \mathrm{C}$ to r.t., overnight; $b$ ) tosyl chloride, $\mathrm{Et}_{3} \mathrm{~N}$, 4-dimethylaminopyridine, $\mathrm{CH}_{2} \mathrm{Cl}_{2}, 0^{\circ} \mathrm{C}$ to r.t., overnight; $\mathrm{c}$ ) phydroquinone, $\mathrm{K}_{2} \mathrm{CO}_{3}, \mathrm{Bu}_{4} \mathrm{NI}, \mathrm{DMF}, 80^{\circ} \mathrm{C}$, overnight; d) anhydrous $\mathrm{MgCl}_{2}$ paraformaldehyde, $\mathrm{Et}_{3} \mathrm{~N}$, THF, reflux, overnight; e) [1] tosyl chloride, $\mathrm{Et}_{3} \mathrm{~N}$, 4dimethylaminopyridine, $\mathrm{CH}_{2} \mathrm{Cl}_{2}, 0^{\circ} \mathrm{C}$ to r.t., $2 \mathrm{~h}$; [2] $\mathrm{NaN}_{3}, \mathrm{DMF}, 80^{\circ} \mathrm{C}$, overnight. PEG4: tetraethylene glycol.

$\mathbf{5}$ in high yield. The hydroxy group of $\mathbf{5}$ was converted into the corresponding tosylate $\mathbf{6}$, which was then used as electrophile for hydroquinone alkylation. To favor the formation of the desired mono-substituted product, 6 was treated with an excess of hydroquinone (2 equiv.) in the presence of potassium carbonate and a catalytic amount of tetrabutylammonium iodide, affording ether $\mathbf{7}$ in good yield.

The latter compound was subjected to the Skattebøl formylation, involving paraformaldehyde, magnesium chloride and triethylamine. ${ }^{[14]}$ Dry reaction conditions and, especially, the use of anhydrous magnesium chloride were crucial for the isolation of $2 \mathrm{HB}$ module 1 in good yields.

2HB module 2 was prepared following a similar strategy, involving the mono-tosylation of PEG4 followed by substitution with sodium azide to give the PEG-azide intermediate 8. A second tosylation-nucleophilic substitution sequence (with hydroquinone as nucleophile) gave phenol 10, which was converted into the corresponding aldehyde $\mathbf{2}$ in good yield.

The synthesis of the carboxylate-bearing 2HB-PEG module 3 was performed starting from triethylene glycol (PEG3) following the route shown in Scheme 3. PEG3 was deprotonated using sodium hydride and then reacted with tert-butyl bromoacetate affording ether 11 in moderate yield (40\%, in agreement with literature data). ${ }^{[17]}$ Compound 11 was then converted into the corresponding tosylate 12 and reacted with hydroquinone as described previously. Interestingly, the tert-butyl ester proved to be unstable under the Skattebøl conditions (probably due to the presence of Lewis acidic $\mathrm{MgCl}_{2}$ ), and the desired 2HB-PEG module $\mathbf{3}$ was isolated directly as free carboxylic acid. While previous results confirm that $2 \mathrm{HB}$ tags bearing alkyne and azide reactive handles (as in 1 and 2 ) are compatible with copper-
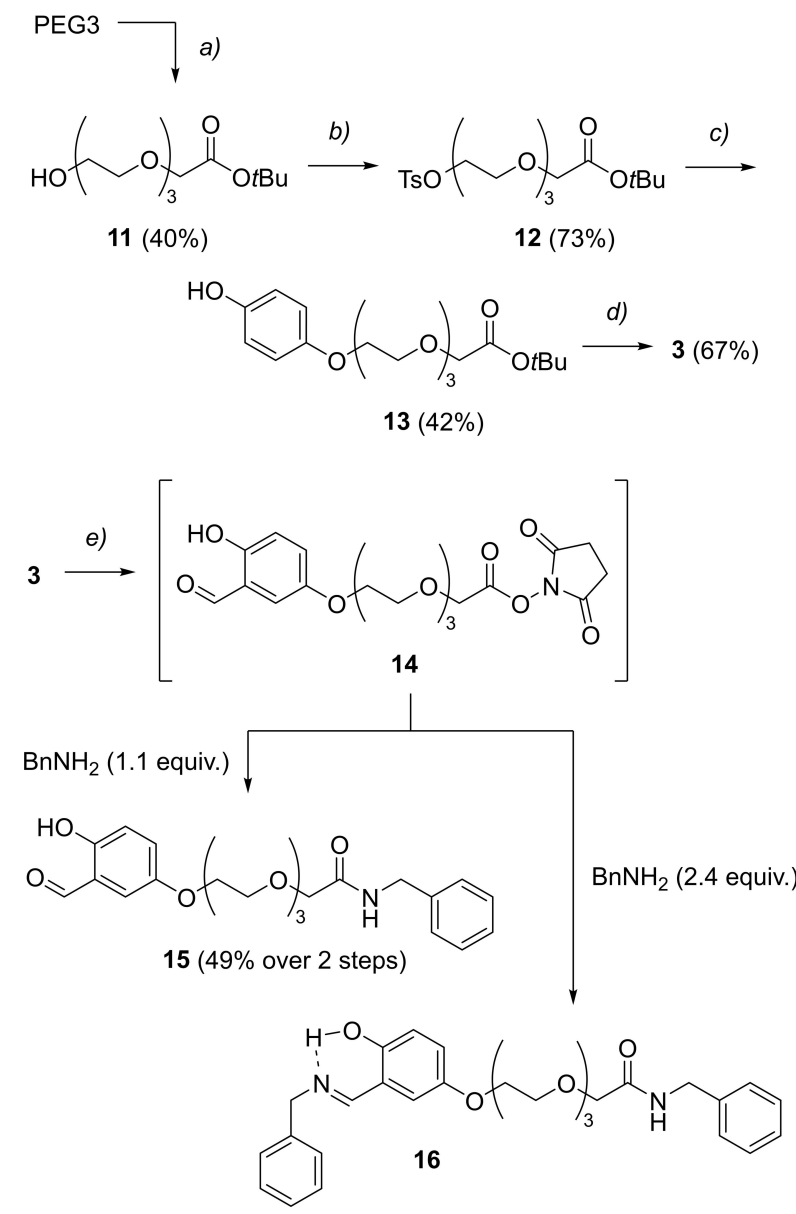

Scheme 3. Synthesis of $2 \mathrm{HB}$-spacer module 3 and its model benzylamide derivative 15. Reagents and conditions: a) [1] $\mathrm{NaH}, \mathrm{DMF}, 0^{\circ} \mathrm{C}$ to r.t., 1 h; [2] tert-butyl bromoacetate, 2 h, r.t.; b) tosyl chloride, $\mathrm{Et}_{3} \mathrm{~N}$, 4-dimeth-

ylaminopyridine, $\mathrm{CH}_{2} \mathrm{Cl}_{2}, 0^{\circ} \mathrm{C}$ to r.t., overnight; c) hydroquinone, $\mathrm{K}_{2} \mathrm{CO}_{3}, \mathrm{Bu}_{4} \mathrm{NI}$, $\mathrm{DMF}, 80^{\circ} \mathrm{C}$, overnight; d) anhydrous $\mathrm{MgCl}_{2}$, paraformaldehyde, $\mathrm{Et}_{3} \mathrm{~N}, \mathrm{THF}$, reflux, overnight; e) [1] $\mathrm{N}$-hydroxysuccinimide, $\mathrm{EDC} \cdot \mathrm{HCl}, \mathrm{CH}_{2} \mathrm{Cl}_{2}, 0^{\circ} \mathrm{C}$ to r.t., overnight; [2] benzylamine, $\mathrm{iPr}_{2} \mathrm{NEt}$, r.t., 2 h. PEG3: triethylene glycol.

catalyzed alkyne-azide cycloadditions, ${ }^{[10]}$ the feasibility to conjugate carboxylic acid 3 to amine-bearing ligands had to be tested experimentally in a model amide coupling reaction. Following a well-known activation strategy, compound $\mathbf{3}$ was converted into the corresponding $\mathrm{N}$-hydroxysuccinimidyl (NHS) ester 14, which was treated with benzylamine as a model nucleophile. Interestingly, in the presence of excess benzylamine ( 2.4 equiv.), the NHS ester was fully converted but imine 16 was the only isolated product after flash chromatography, thus confirming the remarkable stability of $2 \mathrm{HB}$ imines (Scheme 3). Decreasing the excess of benzylamine down to 1.1 equiv., and performing an acidic work up followed by reverse-phase HPLC, the desired amide 15 was obtained in $49 \%$ isolated yield (Scheme 3).

Finally, the preparation of the 2HB-PEG module 4, bearing a free amine residue, was attempted by catalytic hydrogenation of azide $\mathbf{2}$ carried out with $\mathrm{Pd} / \mathrm{C}$ in the presence of acetic acid in $\mathrm{THF} / \mathrm{H}_{2} \mathrm{O}$. However, the reaction led to the formation of a yellow solid that was poorly soluble in most solvents except water. 
NMR analysis suggested that this material (compound 17 in Scheme 4A) was a mixture of head-tail oligomers of compound 4 , assembled by formation of multiple imine bonds. ${ }^{[18]}$ In the attempt to revert the oligomerization, we treated compound 17 with the activated ester Fmoc-Ala-OSu in the presence of $i \mathrm{Pr}_{2} \mathrm{NEt}$, but we met with no success. ${ }^{[19]}$ To prevent the oligomerization, we carried out the catalytic hydrogenation of azide 2 under basic conditions $\left(\mathrm{Pr}_{2} \mathrm{NEt}\right)$ in THF/water and in the presence of Fmoc-Ala-OSu (Scheme 4A). While the azide reduction proceeded smoothly, no amide 18 was formed and oligomer 17 was again isolated as the main product.

Since the preparation of a reactive amine handle on the $2 \mathrm{HB}$ tag proved troublesome, we explored the use of a protecting group to temporarily silence the $2 \mathrm{HB}$ reactivity during tag conjugation, while restoring its properties at a later stage. As shown in Scheme $4 B$, the phenolic group in com-
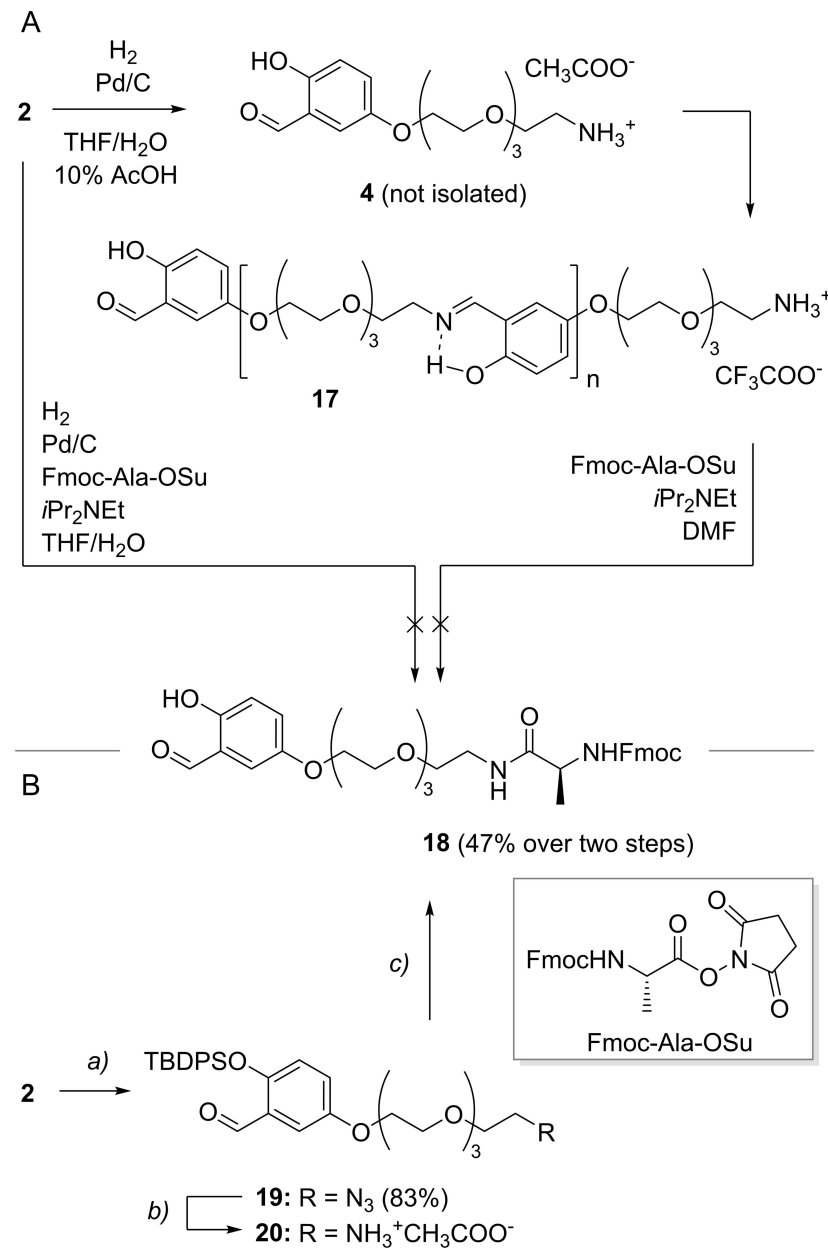

Scheme 4. A) Initial synthetic plan for the preparation of the 2HB-module 4 the catalytic hydrogenation of azide 2 resulted in a water-soluble material (17, consisting in head-tail oligomers of amine-aldehyde 4 ) which proved unreactive towards amide bond formation in the presence of the NHSactivated ester Fmoc-Ala-OSu. B) Synthesis of the 2HB-spacer-amide conjugate 18, carried out via phenol protection. Reagents and conditions: $a$ ) $t$-butyldiphenylsilyl chloride, $\mathrm{Et}_{3} \mathrm{~N}$, 4-dimethylaminopyridine, $\mathrm{CH}_{2} \mathrm{Cl}_{2}, 0^{\circ} \mathrm{C}$ to r.t., overnight; b) $\mathrm{H}_{2}, \mathrm{Pd} / \mathrm{C}, 1: 1 \mathrm{THF} / \mathrm{H}_{2} \mathrm{O}+10 \%$ acetic acid, r.t, 2 h; c) [1] Fmoc-Ala-OSu, $\mathrm{NaHCO}_{3}$, DMF/water, r.t., overnight [2] RP-HLPC with water/ acetonitrile mixtures $+0.1 \%$ TFA. pound 2 was converted into the corresponding tert-butyldiphenylsilyl (TBDPS) ether 19, which was then subjected to catalytic hydrogenation, leading to the primary amine acetate salt 20 . The absence of oligomeric products was confirmed by NMR analysis in deuterium oxide. As depicted in Figure 2, the NMR spectrum of 20 in the $8-10.5$ ppm range showed only the presence of a singlet peak corresponding to the formyl $\mathrm{H}$ atom.

Finally, compound $\mathbf{2 0}$ was successfully coupled with FmocAla-OSu in DMF/water, using sodium bicarbonate as base. Delightfully, the amide product underwent desilylation during the RP-HPLC purification (probably due to the presence of diluted TFA in the eluent), and the 2HB derivative 18 was obtained directly in $47 \%$ isolated yield.

In conclusion, we explored the functionalization of the Lys $\varepsilon$-amino group-engaging $2 \mathrm{HB}$ tag with PEG spacers and four different reactive handles commonly used in bioconjugation protocols, such as cycloaddition reactions and amide couplings. The $2 \mathrm{HB}$ tag was efficiently installed in mono-alkylated hydroquinones through the Skattebøl formylation, which proved a valid alternative to the poorly regioselective alkylation of dihydroxybenzaldehyde derivatives. The preparation of $2 \mathrm{HB}-$ PEG modules with alkyne, azide and carboxylic acid handles (compounds 1-3) was straightforward, whereas the high reactivity of $2 \mathrm{HB}$ towards imine formation hampered the isolation of the amine-bearing $2 \mathrm{HB}$ module 4 , due to the formation of oligomers. We circumvented this problem by protecting the phenolic $\mathrm{OH}$ group in compound $\mathbf{2}$ - the azide precursor of 4 - thus silencing the reactivity of the $2 \mathrm{HB}$ group towards imine formation. The protected azide 19 could be readily reduced to give the corresponding amine, which was successfully coupled with an activated ester. The silyl protecting group was removed during the RP-HPLC purification of the resulting amide, without the need of a dedicated step.

The synthetic procedures described herein are applicable to the preparation of a large variety of $2 \mathrm{HB}$-spacer modules and

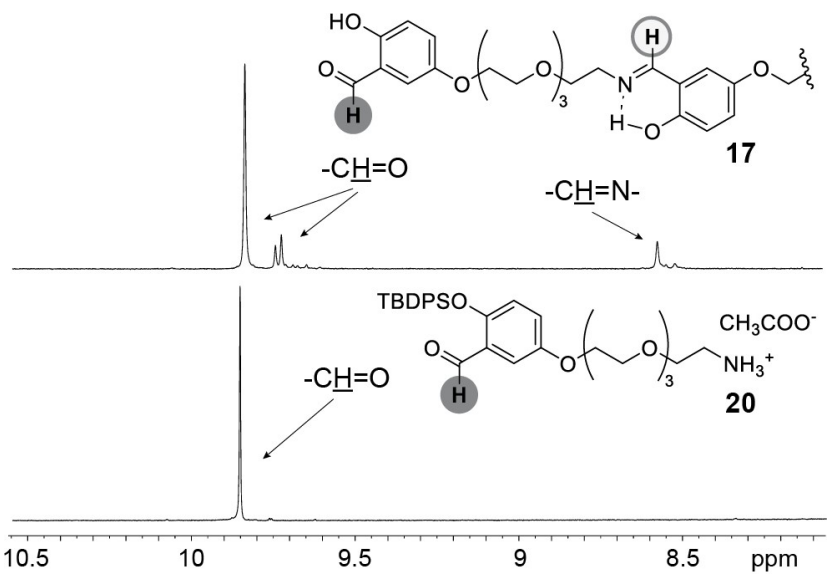

Figure 2. Comparative analysis of the NMR spectra of oligomer 17 and aldehyde 20. (Solvent: deuterium oxide; ppm range: $8-10.5)$. The spectrum of 17 highlighted the presence of multiple aldehyde $(\mathrm{CH}=\mathrm{O})$ and imine $(\mathrm{CH}=\mathrm{N})$ peaks, which indicate the formation of head-to-tail oligomers. On the contrary, phenol protection in compound $\mathbf{2 0}$ led to the detection of a single aldehyde proton, without the presence of undesired imine byproducts. 
their versatile conjugation to virtually any type of protein ligands (e.g. small organic molecules, peptides and peptidomimetics), aiming at the reversible-covalent engagement of Lys $\varepsilon$ amino groups on the targeted protein.

\section{Experimental Section}

The synthetic procedures for the preparation of compounds 1-4 are reported in the Supporting Information, along with the ${ }^{1} \mathrm{H}$ - and ${ }^{13} \mathrm{C}-\mathrm{NMR}$ spectra, and MS spectrometry data.

\section{Acknowledgements}

Giovanni Sacco thanks the University of Milan for a PhD fellowship, Simon Stammwitz (Leibniz Universität Hannover, DE) thanks the European Union for an Erasmus + fellowship. We also gratefully acknowledge Ministero dell'Università e della Ricerca (PRIN 2015 project 20157WW5EH) for financial support.

\section{Conflict of Interest}

The authors declare no conflict of interest.

Keywords: Aldehydes - Conjugation - Regioselectivity · Schiff bases $\cdot$ Skattebøl formylation

[1] a) D. Neri, R. A. Lerner, Annu. Rev. Biochem. 2018, 87, 479-502; b) C. Heinis, G. Winter, Curr. Opin. Chem. Biol. 2015, 26, 89-98; c) C. Zambaldo, S. Barluenga, N. Winssinger, Curr. Opin. Chem. Biol. 2015, 26, 8-15.

[2] a) V. Bandlow, S. Liese, D. Lauster, K. Ludwig, R. R. Netz, A. Herrmann, O. Seitz, J. Am. Chem. Soc. 2017, 139, 16389-16397; b) G. Sacco, A Dal Corso, D. Arosio, L. Belvisi, M. Paolillo, L. Pignataro, C. Gennari, Org. Biomol. Chem. 2019, 17, 8913-8917; c) A. Dias, A. Pina, A. Dal Corso, D. Arosio, L. Belvisi, L. Pignataro, M. Caruso, C. Gennari, Chem. Eur. J. 2017, 23, 14410-14415; d) A. Pina, M. Kadri, D. Arosio, A. Dal Corso, J. Coll, C. Gennari, D. Boturyn, Chem. Eur. J. 2020, 26, 7492-7496.

[3] a) J. Singh, R. C. Petter, T. A. Baillie, A. Whitty, Nat. Rev. Drug Discovery 2011, 10, 307-317; b) T. A. Baille, Angew. Chem. Int. Ed. 2016, 55, 1340813421; Angew. Chem. 2016, 128, 13606-13619.

[4] a) R. Lagoutte, R. Patouret, N. Winssinger, Curr. Opin. Chem. Biol. 2017, 39, 54-63; b) A. Bandyopadhyay, J. Gao, Curr. Opin. Chem. Biol. 2016, 34, $110-116$.

[5] J. Pettinger, K. Jones, M. D. Cheeseman, Angew. Chem. Int. Ed. 2017, 56, 15200-15209; Angew. Chem. 2017, 129, 15398-15408.

[6] a) S. R. Adusumalli, D. G. Rawale, U. Singh, P. Tripathi, R. Paul, N. Kalra, R. K. Mishra, S. Shukla, V. Rai, J. Am. Chem. Soc. 2018, 140, 15114-15123; b) S. R. Adusumalli, D. G. Rawale, K. Thakur, L. Purushottam, N. C. Reddy, N. Kalra, S. Shukla, V. Rai, Angew. Chem. Int. Ed. 2020, 59, 10332-10336; Angew. Chem. 2020, 132, 10418-10422; c) M. Wolter, D. Valenti, P. J. Cossar, L. M. Levy, S. Hristeva, T. Genski, T. Hoffmann, L. Brunsveld, D. Tzalis, C. Ottmann, Angew. Chem. Int. Ed. 2020, 59, 21520-21524; Angew. Chem. 2020, 132, 21704-21708; d) A. Märcher, J. Palmfeldt, M. Nisavic, K. V. Gothelf, Angew. Chem. Int. Ed. 2021, 60, 6539-6544; Angew. Chem. 2021, 133, 6613-6618.
[7] P. M. S. D. Cal, J. B. Vicente, E. Pires, A. V. Coelho, L. F. Veiros, C. Cordeiro, P. M. P. Gois, J. Am. Chem. Soc. 2012, 134, 10299-10305.

[8] G. Akçay, M. A. Belmonte, B. Aquila, C. Chuaqui, A. W. Hird, M. L. Lamb, P. B. Rawlins, N. Su, S. Tentarelli, N. P. Grimster, Q. Su, Nat. Chem. Biol. 2016, 12, 931-936.

[9] Figure 1B: Protein: BIR domain of melanoma inhibitor of apoptosis (MLIAP), Protein Data Bank (PDB): 3F7G, see: a) F. Cohen, B. Alicke, L. O. Elliott, J. A. Flygare, T. Goncharov, S. F. Keteltas, M. C. Franklin, S. Frankovitz, J. P. Stephan, V. Tsui, D. Vucic, H. Wong, W. J. Fairbrother, J. Med. Chem. 2009, 52, 1723-1730; Figure 1C: Protein: integrin $\alpha_{v} \beta_{3}$, PDB: 1 L5G, see: b) J.-P. Xiong, T. Stehle, R. Zhang, A. Joachimiak, M. Frech, S. L. Goodman, M. A. Arnaout, Science 2002, 296, 151-155; Figure 1D: Protein: type 1 interleukin-1 receptor, PDB: 1GOY, see: c) G. P. Vigers, D. J. Dripps, C. K. Edwards III, B. J. Brandhuber, J. Biol. Chem. 2000, 275, 36927-36933; Figure 1E: Protein: Histone-binding protein RBBP4, PDB: 6ZRD, see: d) P. Hart, P. Hommen, A. Noisier, A. Krzyzanowski, D. Schüler, A. T. Porfetye, M. Akbarzadeh, I. R. Vetter, H. Adihou, H. Waldmann, Angew. Chem. Int. Ed. 2021, 60, 1813-1820; Angew. Chem. 2021, 133, 1841-1848.

[10] A. Dal Corso, M. Catalano, A. Schmid, J. Scheuermann, D. Neri, Angew. Chem. Int. Ed. 2018, 57, 17178-17182; Angew. Chem. 2018, 130, 1742417428. This work includes a comparative analysis of the reactivity of different benzaldehyde derivatives (including 2-formyl-phenylboronic acid and $2 \mathrm{HB}$ ) towards imine bond formation with $N_{\alpha}$-acetyl-lysine in aqueous buffer at $\mathrm{pH}$ 7.4. ${ }^{1} \mathrm{H}$ NMR spectra were recorded to quantify the percentage of hydration product and/or imine formation, leading to the calculation of dissociation constants and to a final ranking of the intrinsic aldehyde reactivity.

[11] The $2 \mathrm{HB}$ fragment is also installed in the drug voxelotor (Oxbryta ${ }^{\mathrm{TM}}$, recently approved for the treatment of sickle cell disease), which prevents the polymerization of mutant hemoglobin $(\mathrm{HbS})$ by forming an imine bond between $2 \mathrm{HB}$ and the amino group of an $\mathrm{N}$-terminal valine residue, see: B. Metcalf, C. Chuang, K. Dufu, M. P. Patel, A. SilvaGarcia, C. Johnson, Q. Lu, J. R. Partridge, L. Patskovska, Y. Patskovsky, S. C. Almo, M. P. Jacobson, L. Hua, Q. Xu, S. L. Gwaltney, C. Yee, J. Harris, B. P. Morgan, J. James, D. Xu, A. Hutchaleelaha, K. Paulvannan, D. Oksenberg, Z. Li, ACS Med. Chem. Lett. 2017, 8, 321-326.

[12] a) E. C. Dreaden, S. C. Mwakwari, Q. H. Sodji, A. K. Oyelere, M. A. ElSayed, Bioconjugate Chem. 2009, 20, 2247-2253; b) B. Huang, A. Desai, S. Tang, T. P. Thomas, J. R. Baker, Org. Lett. 2010, 12, 1384-1387.

[13] M. G. Gichinga, S. Striegler, Tetrahedron 2009, 65, 4917-4922.

[14] T. V. Hansen, L. Skattebøl, Org. Synth. 2005, 82, 64-68.

[15] While the terminal alkyne group is mainly used in copper-catalyzed Huisgen cycloadditions (see: E. Lallana, R. Riguera, E. Fernandez, Angew. Chem. Int. Ed. 2011, 50, 8794-8804; Angew. Chem. 2011, 123, 89568966), azides have been exploited for a wider range of ligation protocols, see: a) B. L. Oliveira, Z. Guo, G. J. L. Bernardes, Chem. Soc. Rev. 2017, 46, 4895-4950; b) J. Tu, M. Xu, R. M. Franzini, ChemBioChem 2019, 20, 1615-1627.

[16] Y. Aeschi, S. Drayss-Orth, M. Valášek, F. Raps, D. Häussinger, M. Mayor, Eur. J. Org. Chem. 2017, 28, 4091-4103.

[17] A. P. Crew, K. Raina, H. Dong, Y. Qian, J. Wang, D. Vigil, Y. V. Serebrenik, B. D. Hamman, A. Morgan, C. Ferraro, K. Siu, T. K. Neklesa, J. D. Winkler, K. G. Coleman, C. M. Crews, J. Med. Chem. 2018, 61, 583-598.

[18] The formation of stable imine bonds with $2 \mathrm{HB}$ derivatives has been used for polymer design, see: J. Huang, H. Zhu, H. Liang, J. Lu, Polym. Chem. 2016, 7, 4761-4770.

[19] Semipreparative RP-HPLC with water/acetonitrile mixtures in the presence of TFA also failed to afford the monomeric product 4 . After liophilization of the eluted fraction, the oligomer 17 was obtained instead.

Manuscript received: February 9, 2021

Revised manuscript received: February 25, 2021

Accepted manuscript online: February 26, 2021 